\title{
X-BAND MAGNICON AMPLIFIER
}

\author{
O. A. Nezhevenko, V. P. Yakovlev, J. L. Hirshfield, and E.V. Kozyrev* \\ Omega-P Inc., 345 Whitney Avenue, New Haven, CT 06511 \\ S.H. Gold and A.W. Fliflet \\ Beam Physics Branch, Plasma Physics Division, \\ Naval Research Laboratory, Washington, DC 20375-5346 \\ A.K. Kinkead \\ Sachs/Freeman Associates, Inc., Landover, MD 20785 \\ R.B. True and R.J. Hansen \\ Litton Systems, Inc., Electron Devices Division, San Carlos, CA 94070
}

\section{INTRODUCTION}

The magnicon is a RF power source with circular beam deflection [1] invented in the 1980's at Budker INP. The first magnicon with the power of $2.6 \mathrm{MW}$ and efficiency of $73 \%$ at $915 \mathrm{MHz}$ was built and tested in the pulse of 30 $\mu \mathrm{sec}$ in 1985 [2]. The second magnicon was developed as a prototype RF source for a linear collider. In order to achieve power of more than $50 \mathrm{MW}$ at $7 \mathrm{GHz}$, the tube was built as a frequency doubling amplifier. The following parameters finally were achieved in 1998: power of $55 \mathrm{MW}$, efficiency of $56 \%$ and the gain of 72 $\mathrm{dB}$ in a pulse of $1.1 \mu \mathrm{sec}$ [3]. The X-band $(11.424 \mathrm{GHz})$ magnicon $[4,5]$ is being developed jointly by Omega-P, Inc. and NRL as a potential high efficiency RF source for the Next Linear Collider (NLC) project. As for the 7 $\mathrm{GHz}$ device, this $11.424 \mathrm{GHz}$ magnicon is a frequency doubling amplifier. The design has been optimized for the parameters of a $500 \mathrm{kV}, 210 \mathrm{~A}, 1 \mu \mathrm{sec}$ modulator with the repetition rate of $10 \mathrm{~Hz}$. This modulator was built for NRL by Titan Beta for a previous project. In this paper, we present a progress report on $11.424 \mathrm{GHz}$ magnicon as well as the results of the gun tests and the beam envelope measurements.

\section{MAGNICON DESIGN}

Fig. 1 shows schematic of the $11.424 \mathrm{GHz}$ magnicon. The tube consists of an electron gun, $6.5 \mathrm{kGs}$ solenoid, RF circuit and collector, insulated from the ground. The 500 $\mathrm{kV}, 210 \mathrm{~A}$ (0.59 microperv) diode gun is designed to obtain the beam area compression of 2500:1 and the beam diameter in the magnet of about $1.5 \mathrm{~mm}$ [6]. The complete RF circuit has six $5.712 \mathrm{GHz}^{\mathrm{TM}} \mathrm{M}_{10}$ deflection cavities (a drive cavity, three gain cavities and two penultimate cavities), followed by an $11.424 \mathrm{GHz} \mathrm{TM}_{210}$ output cavity. The gain and penultimate cavities have inductive measuring probes. In contrast to [3] the two penultimate cavities are not coupled in order to eliminate possible instability [7]. To extract RF power there are two output apertures at the downstream end of the output cavity, separated by $135^{\circ}$, and ending in WR-90 waveguide.

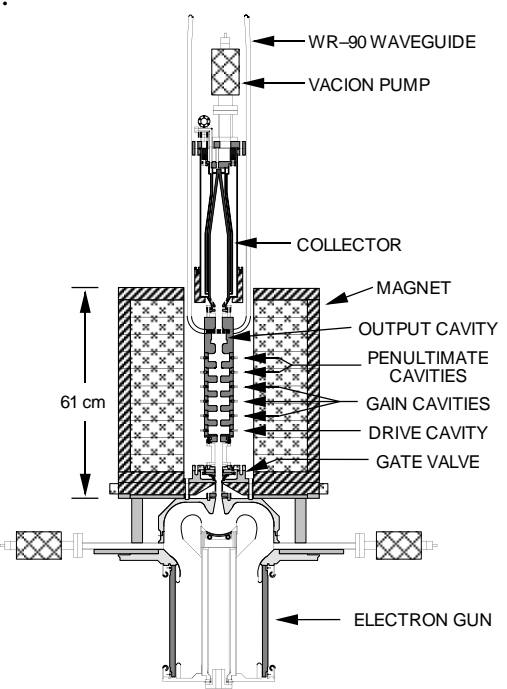

Fig.1 The magnicon schematic.

Special wall perturbations (similar to [3]) to restore quadrupole symmetry are employed. The tube does not have output windows and WR-90 waveguides are connected to the SLAC-type vacuum loads directly. The gun, RF circuit and collector are bakable up to $400^{\circ} \mathrm{C}$. The gun is supplied with the gate valve (bakable also) in order to protect the cathode while changing experimental setups: the gun tests, the beam measurements, the tests of the complete tube, etc.. The magnicon design parameters are given in the Table 1. Beam dynamics simulations in the magnicon in both time-dependent and steady-state regimes were performed using computer code [8]. The physical model includes: realistic RF fields in the cavities and DC magnetic fields, finite beam size and multiple reflection of electrons from the collector surface. The code SLANS2 [9] was used for RF field calculations, the codes DEMEOS [10] and SUPERSAM [11] were used for the gun optimization, and the code SAM [12] was

\footnotetext{
* Permanent address: Budker INP, Novosibirsk 630090, Russia
} 
used for calculation of DC magnetic field and fields in the gun. The optimization of the tube was done taking into account possible instabilities and excitation of different parasitic modes in the cavities.

Table 1

\begin{tabular}{|l|ll|}
\hline Frequency & 11.424 & $\mathrm{GHz}$ \\
Power & 66 & $\mathrm{MW}$ \\
Efficiency & 63 & $\%$ \\
Pulse duration & 1 & $\mu \mathrm{s}$ \\
Repetition rate & 10 & $\mathrm{~Hz}$ \\
Gain & 62 & $\mathrm{~dB}$ \\
Drive frequency & 5.712 & $\mathrm{GHz}$ \\
Drive power & 40 & $\mathrm{~W}$ \\
Beam voltage & 500 & $\mathrm{kV}$ \\
Beam current & 210 & $\mathrm{~A}$ \\
Microperveance & 0.59 & \\
Beam diameter in the magnet & 1.5 & $\mathrm{~mm}$ \\
Beam area compression & $2500: 1$ & \\
\hline
\end{tabular}

The simulations of the beam dynamics in the magnicon were done neglecting space charge effects, which should be small according to estimates. Besides, experiments [3] show excellent agreement with the simulation results even for higher microperveance of 0.88 .

\section{THE GUN TESTS}

The electron gun [6] was designed jointly by Omega-P and Litton Electron Devices, and fabricated by Litton. A 75-mm diameter, $30^{\circ}$-half-angle dispenser cathode was used, with a maximum cathode loading of $\sim 5 \mathrm{~A} / \mathrm{cm}^{2}$. The maximum focus-electrode gradient is $<190 \mathrm{kV} / \mathrm{cm}$, which should allow pulse length greater than $3 \mu \mathrm{sec}$. A unique feature of the gun is use of an electrically isolated focus electrode biased negatively with respect to the cathode [13]. This serves to reduce beam halo and helps to overcome the effect of gun tolerances [6]. The electron gun underwent initial high voltage tests in June 1998. It was immediately determined that the gun microperveance exceeds 1 . This meant that the anode-cathode (A-K) gap was substantially smaller than the design value. An assembly error in the gun fabrication was discovered. The gun was cut open and rewelded with an additional spacer to correct the A-K gap back to its design value. However, measurements made on the repaired gun still show excessive current, corresponding to a microperveance of $\sim 0.64$. This higher perveance is attributed to more cathode and focusing electrode expansion, than was accounted for during fabrication, based on expansion measurements that were carried out after $\sim 0.5$ hours of heater operation. The final perveance value (see Fig. 2) is reached after 2-2.5 hours of heater operation. This error in A-K gap leads to a beam optics change, mismatching with magnetic field and beam diameter increase. In order to correct this effect and to make the beam diameter close to its design value, the magnetic field profile was changed by means of an iron corrector plate in the magnet (see Fig.3).

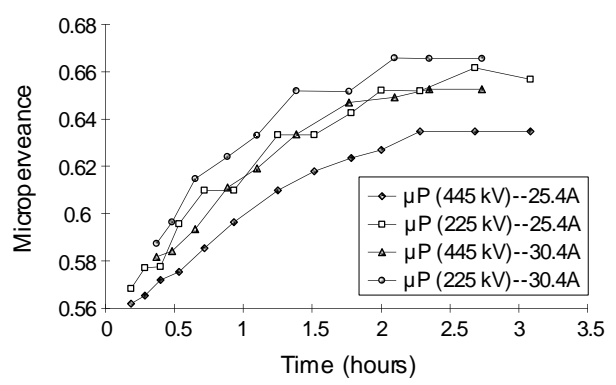

Fig. 2 Perveance vs time for different beam voltage and heater current

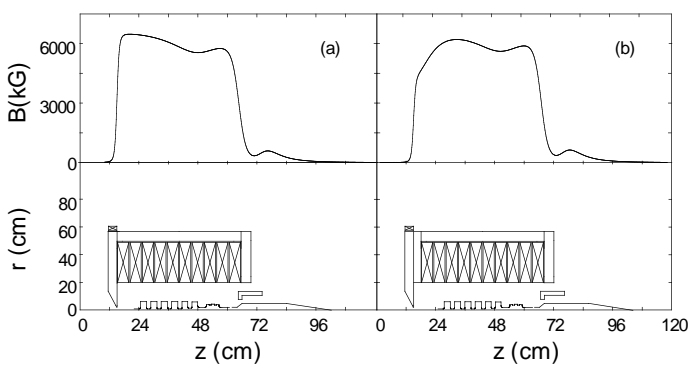

Fig. 3. Original magnetic field profile (a), and magnetic field profile with corrector plate (b).

\section{THE BEAM MEASUREMENTS}

In order to characterize and optimize the electron beam, a high-vacuum bakable beam analyzer was designed and built. It is similar to one reported in [14]. Schematic of the analyzer is shown in Fig. 4. The location of the beam edges is determined by using a set of $8 \mathrm{~mm}$-wide graphite apertures (Fig. 4) that are translated laterally until they

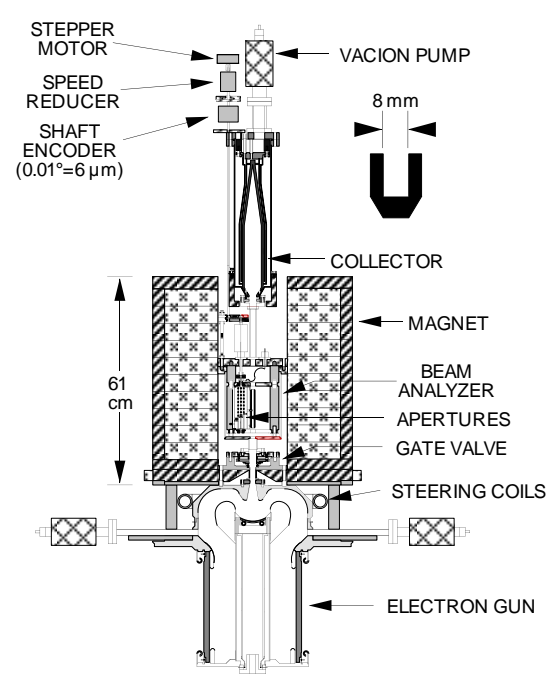

Fig. 4 Beam analyzer

just begin to collect current from the edge of the beam. The analyzer has a rotating cylinder with 12 equallyspaced angular positions. Ten of these positions are used to position graphite apertures at $10-\mathrm{mm}$ intervals along 
the axis of the device. The remaining two angular positions support 100-mm-long graphite tubes with 4-mm and 8 -mm inner diameters, that can be used to measure total beam interception. In order to measure intercepted current, the rotating cylinder is electrically isolated from the ground. The cylinder is rotated by a stepper-motor. The angular position is measured to $0.1^{\circ}$ accuracy using an absolute shaft encoder, corresponding to a displacement of $\sim 60 \mu \mathrm{m}$. The beam measurements show that minimal achieved transverse beam size exceeds the design value. Measured beam envelopes for optimal case are shown in the Fig. 5. One can see that the beam is not axially symmetric. The current density on the one side of the beam rises rapidly, while on the other side the current density is more gradual.

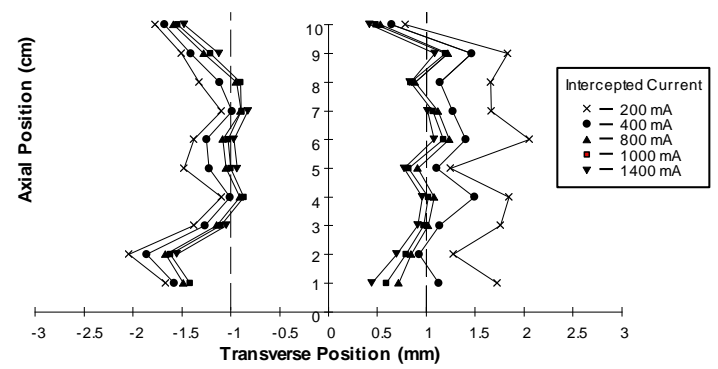

Fig. 5 The measured beam envelopes.

This minimum beam size was achieved for negative focus electrode biasing of $100 \mathrm{~V}$. In the Fig. 6 the beam size dependence on the focus bias voltage is shown. Measurements show an apparent misalignment between cathode and focus electrode: large beam diameter; asymmetric beam edges; increased focus electrode biasing makes this worse; steering coils (Fig. 4) make only small improvements.

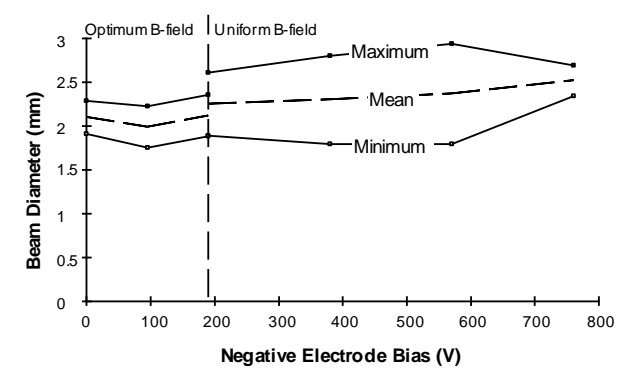

Fig. 6 Beam size vs focus electrode bias.

Additional evidence of this transverse misalignment is shown by measurement of the beam centroid position (Fig. 7). One may see an increase of the beam centroid displacement off the axis when bias voltage is increased.

\section{SUMMARY}

At present the magnicon gun is conditioned and tested up to a voltage of $480 \mathrm{kV}$, which is considered as an adequate level for reliable operation of the modulator. The measurements of the beam size have been completed. Due to gun manufacturing errors, the transverse beam size is $~ 2.3 \mathrm{~mm}$ instead of design value of $1.5 \mathrm{~mm}$. The beam area compression remains high (1100:1) and current density exceeds $6 \mathrm{kA} / \mathrm{cm}^{2}$. The measured increase in beam size leads to some decrease in efficiency. Newly calculated magnicon design parameters for the measured beam are presented in Table 2 .

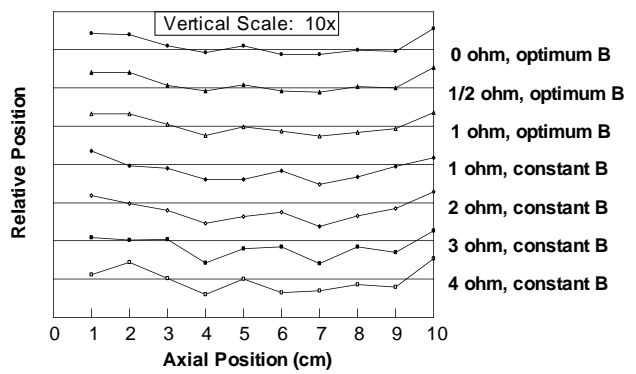

Fig. 7 Beam centroid at $1 \mathrm{~A}$ intercepted current. Negative bias voltage equals to $\sim 200 \mathrm{~V} / \mathrm{Ohm}$.

Table 2

\begin{tabular}{|l|ll|}
\hline Power & 56 & MW \\
Efficiency & 55 & $\%$ \\
Gain & 59 & $\mathrm{~dB}$ \\
Beam voltage & 480 & $\mathrm{kV}$ \\
Beam current & 210 & $\mathrm{~A}$ \\
\hline
\end{tabular}

The RF structure fabricated at Budker INP (Novosibirsk) has been delivered and is being prepared for high power tests. It is expected that high power conditioning of the magnicon tube will begin in April, 1999.

\section{ACKNOWLEDGMENTS}

This research was supported by the US DoE SBIR contract DEFG002-95-ER-82045, and DoE and ONR under Interagency Agreement DE-AI02-94ER40861. We are grateful to Dr. G. Caryotakis of SLAC for the contribution of several high-power microwave output components for magnicon.

\section{REFERENCES}

[1] O.A. Nezhevenko, IEEE Tr. Plasma Sci.,. 22, p.756, 1994.

[2] M.M. Karliner, et al., NIM, vol. A269, pp. 459-473, 1988.

[3] E.V. Kozyrev, et al., Proc.EPAC 98, pp. 1897-1899, 1998.

[4] S.H. Gold, et al., Phys. Plasmas 4, p. 1900, 1997.

[5] S.H. Gold, et al., Proc. PAC 97, pp. 3153-3155, 1997.

[6] V.P. Yakovlev, et al., Proc. PAC 97, pp. 3186-3188, 1997.

[7] O.A. Nezhevenko and V.P. Yakovlev, to be published.

[8] V.P. Yakovlev, et al., Proc. PAC 95, pp. 1569-1571, 1995.

[9] D.G. Myakishev, et al., Proc. PAC 95, pp. 2348-2350, 1995.

[10] R.B. True, "Electron Beam Formation, Focusing and Collection in Microwave Tubes," Academic Press, v.1, p.497, 1995.

[11] D.G. Myakishev, et al., Int. J. Mod. Phys., 2, pp. 915-917, 1993.

[12] M.A. Tiunov, et al., Proc. $13^{\text {th }}$ Int. Conf. High Energy Acc.,1, p.387,1987.

[13] R.B. True, et al., IEEE Microwave Power Tube Conf., Monterey. CA, May 1996.

[14] Y.V. Baryshev, et al., NIM, vol. A340, pp. 241-258, 1994. 